\title{
A Case of Buccal Clear Cell Carcinoma Caused by Rare Fusion Gene: EWSR1-CREM
}

\author{
Miyako Hoshino $\mathbb{D}^{1},{ }^{1}$ Katsuyuki Inoue, ${ }^{2}$ Tomohisa Kaneda, ${ }^{2}$ Michiko Nishimura, ${ }^{1}$ \\ Kaoru Kusama, ${ }^{1}$ Hideaki Sakashita, ${ }^{2}$ Yukiko Sato $\mathbb{D}^{3,4}{ }^{3,4}$ Kengo Takeuchi, ${ }^{3,4,5}$ \\ Toshitaka Nagao, ${ }^{6}$ and Kentaro Kikuchi ${ }^{1}{ }^{1}$
}

${ }^{1}$ Division of Pathology, Department of Diagnostic and Therapeutic Sciences, Meikai University School of Dentistry, 1-1 Keyakidai, Sakado, Saitama 350-0283, Japan

${ }^{2}$ Second Division of Oral and Maxillofacial Surgery, Department of Diagnostic and Therapeutic Sciences, Meikai University School of Dentistry, 1-1 Keyakidai, Sakado, Saitama 350-0283, Japan

${ }^{3}$ Division of Pathology, Cancer Institute, Japanese Foundation for Cancer Research, 3-8-31 Ariake, Koto-ku, Tokyo 135-8550, Japan

${ }^{4}$ Department of Pathology, Cancer Institute Hospital, Japanese Foundation for Cancer Research, 3-8-31 Ariake, Koto-ku, Tokyo 135-8550, Japan

${ }^{5}$ Pathology Project for Molecular Targets, Cancer Institute, Japanese Foundation for Cancer Research, 3-8-31 Ariake, Koto-ku, Tokyo 135-8550, Japan

${ }^{6}$ Department of Anatomic Pathology, Tokyo Medical University, 7-3-1 Hongo, Bunkyo-ku, Tokyo 113-0033, Japan

Correspondence should be addressed to Miyako Hoshino; miyako-h@dent.meikai.ac.jp

Received 1 February 2021; Revised 23 June 2021; Accepted 8 October 2021; Published 20 October 2021

Academic Editor: Mark Darling

Copyright (c) 2021 Miyako Hoshino et al. This is an open access article distributed under the Creative Commons Attribution License, which permits unrestricted use, distribution, and reproduction in any medium, provided the original work is properly cited.

\begin{abstract}
Clear cell carcinoma (CCC) is a rare entity in the salivary gland tumor. So far, only 10 cases of primary CCC of the buccal mucosa have been reported. Here, we first report an extremely rare case of buccal CCC with the EWSR1-CREM fusion gene. The patient, a 69 -year-old woman, presented with a painless mass in the right buccal mucosa. The tumor, which had been present for about 10 years, measured approximately $15 \mathrm{~mm}$ in diameter and was pedunculated, elastic hard, smooth, and mobile. Histopathological examination revealed proliferating tumor cells with vacuolated and clear cytoplasm partially surrounded by hyalinized stroma. The tumor was not encapsulated, and no contact with the overlying epithelium was evident. Duct-like structures were occasionally observed in the tumor nests composed of clear cells. The tumor had invaded into surrounding muscle and adipose tissues. Immunohistochemical examination revealed that the clear cells were positive for epithelial cell markers, and myoepithelial markers were negative. Fluorescence in situ hybridization (FISH), performed to search for genetic abnormalities, demonstrated split positivity for EWSR1, and fusion with CREM was confirmed. These findings suggested a diagnosis of CCC.
\end{abstract}

\section{Introduction}

Clear cell carcinoma (CCC) is an epithelial malignant tumor that arises in the salivary glands. CCC in the salivary glands was first reported in 1994 by Milchgrub et al. [1], who described a low-grade salivary gland carcinoma composed of malignant cells with clear cytoplasm, with hyalinization. CCC has a squamoid phenotype and lacks certain features of other clear cell-rich salivary gland carcinomas. It is more common in women, typically presenting in the fifth to eighth decades of life, and rare in children [2]. CCC is rare and accounts for fewer than $1 \%$ of all malignant tumors in the salivary glands. It occurs most frequently in the intraoral minor salivary glands, the palate, and the base of the tongue and less frequently in the buccal mucosa [3]. CCC most commonly presents as swelling and may be ulcerated or associated with pain, bone invasion, and soft tissue fixation [2]. Histopathologically, CCC is composed of proliferating 


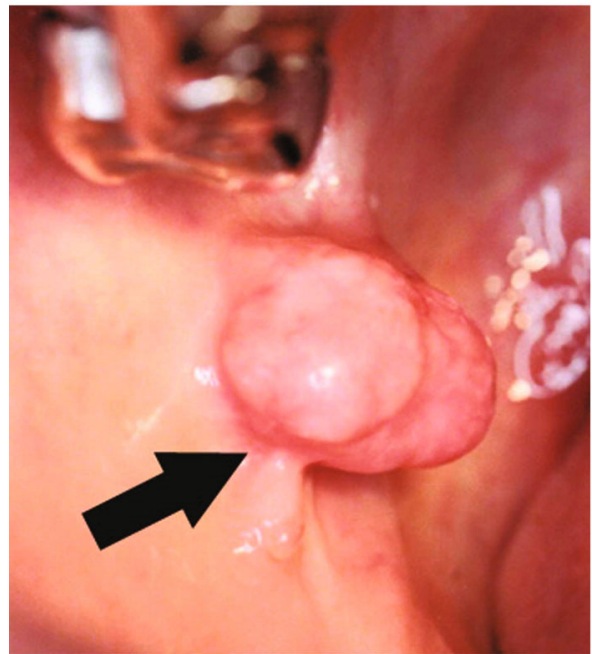

(a)

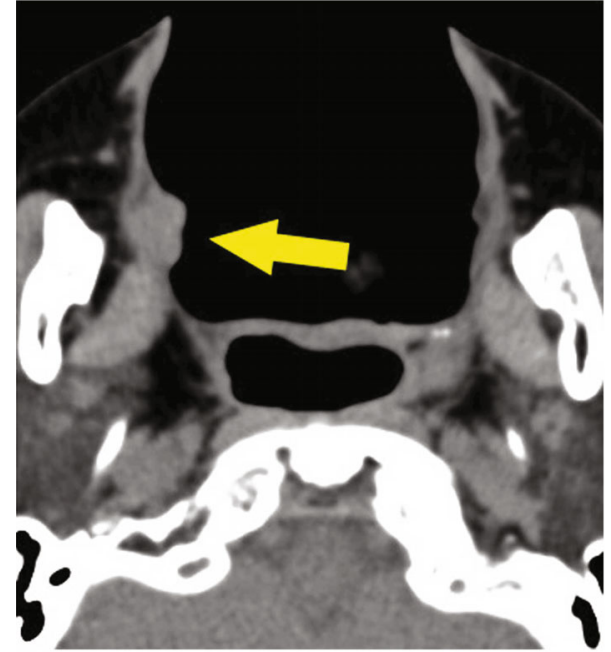

(b)

FIGURE 1: Intraoral appearance of the buccal mucosa and CT image. (a) The mucosal epithelium was normal in color with a smooth surface. There was no induration around the tumor (black arrow). (b) CT (axial view) showed an enhanced lesion on the anterior portion of the right palatoglossal arch (yellow arrow).

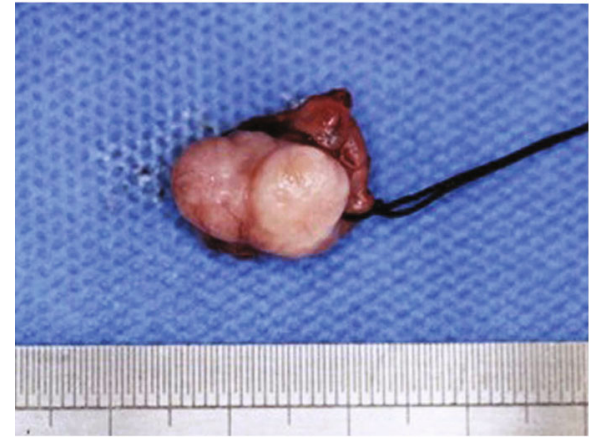

(a)

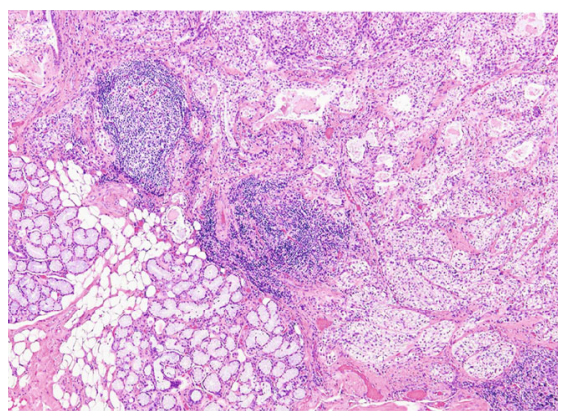

(d)

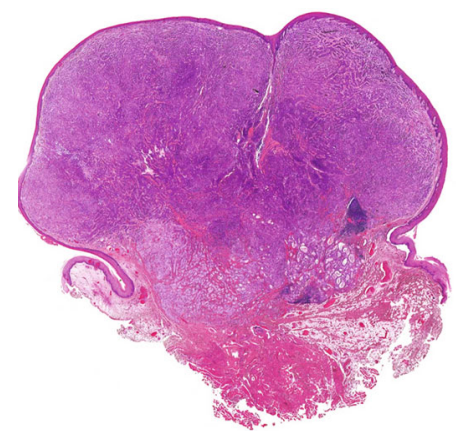

(b)

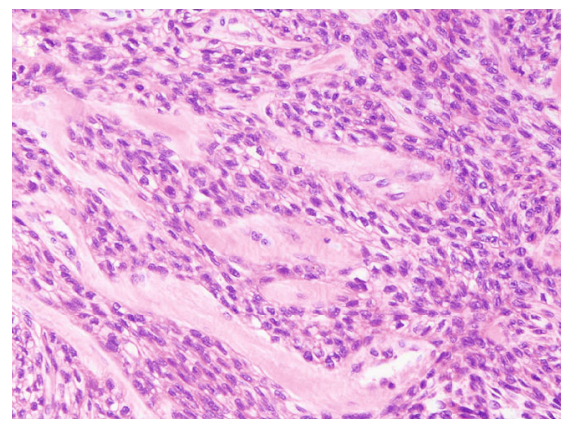

(e)

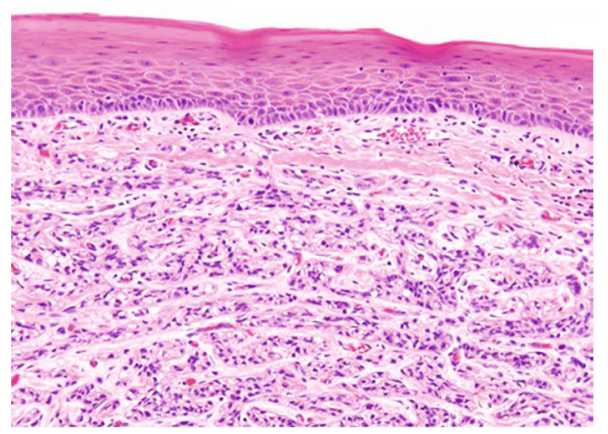

(c)

FIgURe 2: Microscopic and survey view of the surgical resected specimen. (a) Resected specimen measuring $18 \times 12 \times 14 \mathrm{~mm}$. (b, c) The tumor demonstrated proliferation of tumor nests with a fibrous stroma. There was no capsule and no contact with the covering epithelium. (d) The tumor had invaded into surrounding muscle and adipose tissues. (e, f) The tumor nests were composed of epithelioid and clear cells partially surrounded by hyalinized stroma. Features suggestive of transition between the two cell types were observed (HE; original magnification: $(b) \times 1,(c) \times 20$, (d, f) $\times 40$, and $(e) \times 100$ ).

epithelial cells with clear cytoplasm organized into trabeculae, cords, or solid nests surrounded by hyalinized stroma [1]. However, differential diagnosis can be difficult because the microscopic features of CCC frequently overlap with those of other salivary gland tumors and metastatic renal cell carcinoma [3]. EWSR1-ATF1 fusion specific for CCC can be evaluated by RT-PCR as hallmark markers, but in our case, EWSR1-ATF1 fusion was not detected. To our knowledge 


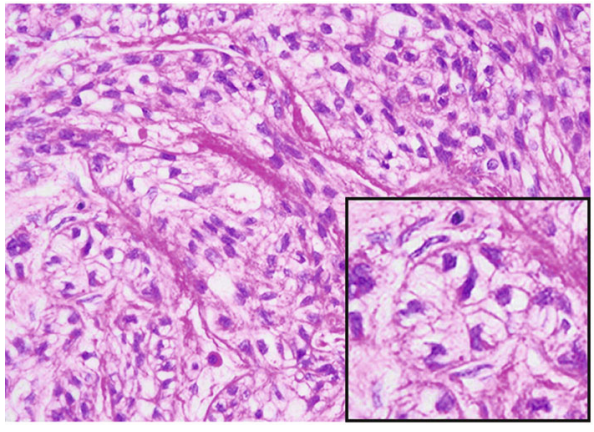

(a)

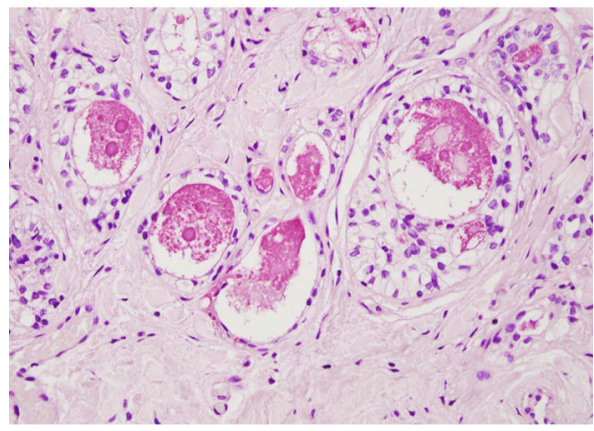

(c)

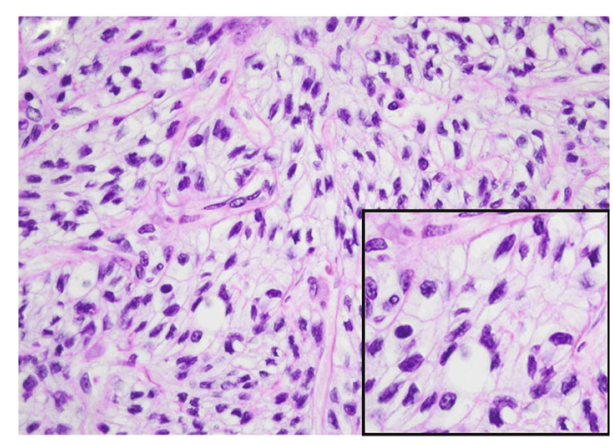

(b)

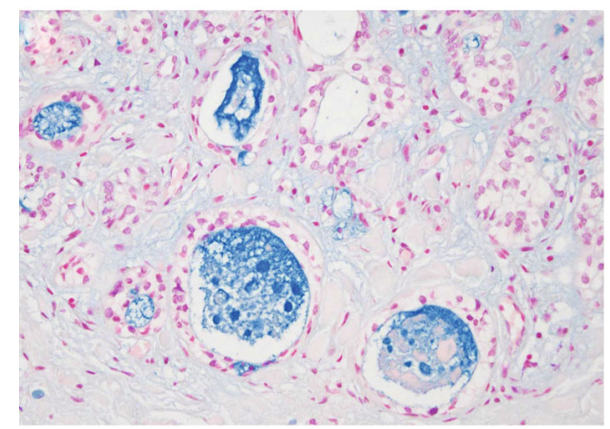

(d)

FIGURE 3: Special stains: (a) PAS, (b) d-PAS, (c) mucicarmine, and (d) Alcian blue. PAS stain shows positive cytoplasmic red material in the clear cells, but PAS with diastase stain was negative, suggesting the presence of glycogen. The contents of duct-like structures were positively stained by mucicarmine and Alcian blue, but mucus-producing cells were not evident in the tumor nests ((a-d) original magnification $\times 200)$.

there are previously 3 reported cases of hyalinizing clear cell carcinomas of EWSR1-CREM fusion [4]; as an additional case report in the literature, here, we first report a very rare case of buccal CCC with the EWSR1-CREM fusion gene.

\section{Case Report}

A 69-year-old woman presented with a mass in the right buccal mucosa that had been present for about 10 years and untreated because of absence of any pain.

However, as it showed no tendency to improve, and the swelling worsened, she visited a local dentist at first. She was then referred to the Meikai University Hospital for detailed examination and treatment. At the first visit, examination of the oral cavity demonstrated a mass measuring $15 \times 10 \mathrm{~mm}$ in the right buccal mucosa on the anterior portion of the lobular polypoid palatoglossal arch (Figure 1(a)). The mucosal epithelium was normal in color with a smooth surface. There was no induration around the tumor. CT showed an enhanced lesion on the anterior portion of the right palatoglossal arch (Figure 1(b)). Surgical excision of the tumor was performed under local anesthesia. The surgical specimen measured $18 \times 12 \times 14 \mathrm{~mm}$ (Figure 2(a)). Histopathologically, the tumor showed proliferation of tumor nests with fibrous stroma. There was no capsule and no contact with the covering epithelium
(Figures 2(b) and 2(c)). The tumor invaded surrounding structures such as muscle and adipose tissue (Figure 2(d)).

The tumor nests were composed of epithelioid and clear cells with partially hyalinized stroma (Figures 2(e) and 2(f)). Mitotic figures were rarely evident, and transition between the two cell types was observed in part (data not shown).

Intracytoplasmic fine granules were positive for periodic acid-Schiff (PAS) and were negative for diastase-sensitive PAS (Figures 3(a) and 3(b)). The contents of duct-like structures were positively stained by mucicarmine and Alcian blue, but mucus-producing cells were not evident in the tumor nests (Figures 3(c) and 3(d)). Immunohistochemically, the tumor cells were strongly positive for AE1/AE3 (Figure 4(a)), CK5/6, and p63 (Figure 4(b)), but negative for $\alpha$-SMA and S100 (Figure 4(c)), and Ki-67-positive cells were rarely found in the tumor nests (Figure 4(d)). The EWSR1-ATF1 fusion gene could not be detected by reverse transcription polymerase chain reaction (RT-PCR) in the present case. RT-PCR also failed to detect the CRTC1/3MAML2 fusion gene, which is specific for mucoepidermoid carcinoma. Using bacterial artificial chromosome clonederived DNA probes for EWSR1 and CREM (the names of BAC clones used will be provided upon request), fluorescence in situ hybridization (FISH) analysis revealed the presence of EWSR1-CREM (Figures 5(a)-5(c)). These findings suggested a diagnosis of CCC with CREM fusion instead of $A T F 1$ fusion. 


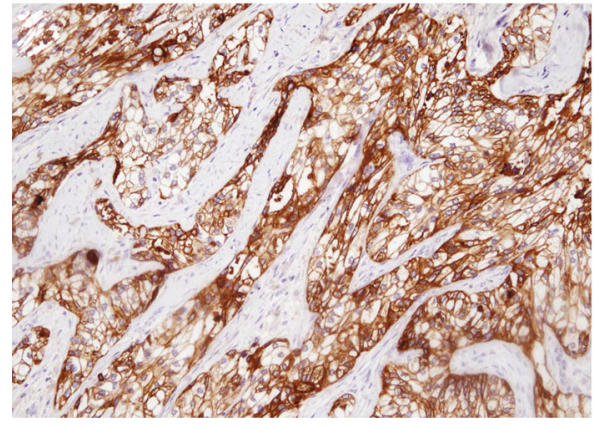

(a)

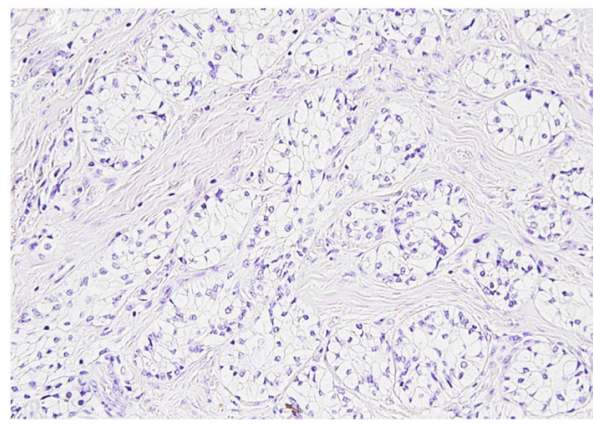

(c)

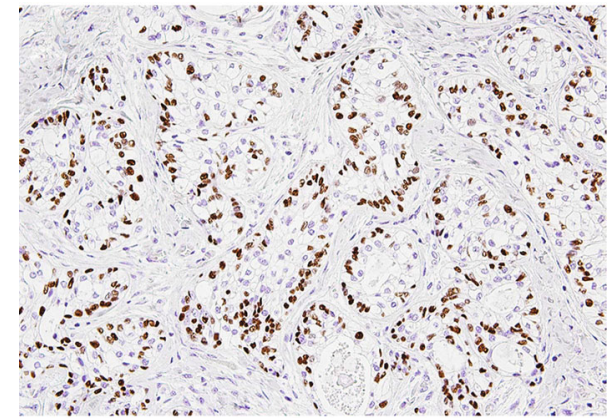

(b)

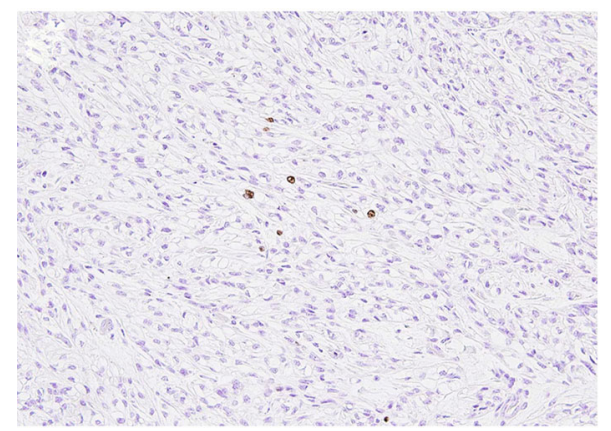

(d)

FIGURE 4: Immunohistochemical findings: (a) pancytokeratin (AE1/AE3), (b) p63, (c) S100, and (d) Ki-67. The tumor cells were stained intensely with cytokeratins, but not myoepithelial markers. The nuclei of the clear cells were positive for p63. Ki-67-positive cells were rarely found in the tumor nests $((\mathrm{a}-\mathrm{d})$ original magnification $\times 200)$.

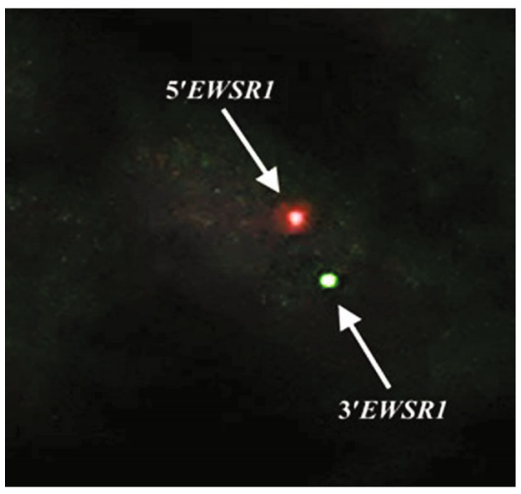

(a)

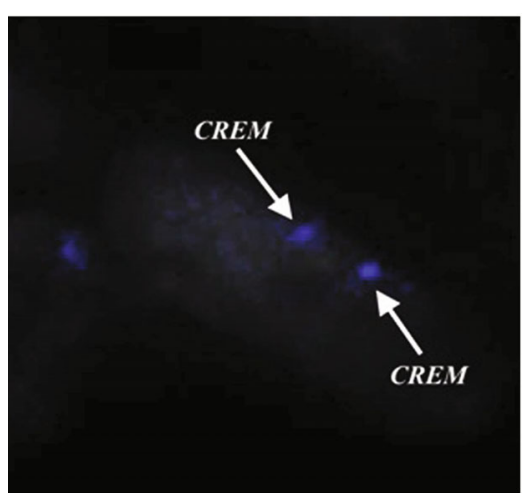

(b)

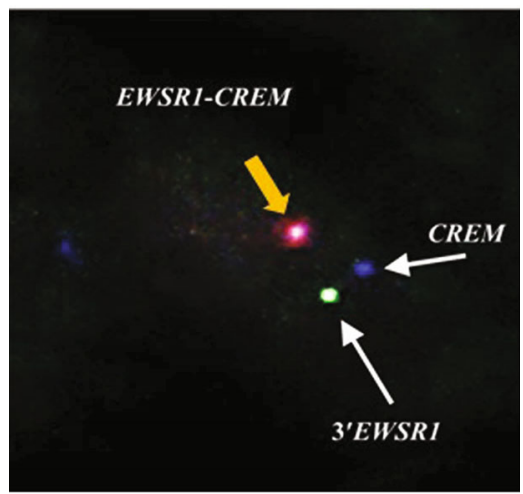

(c)

FIGURE 5: FISH analysis: (a) EWSR1 break-apart; (b) CREM; (c) EWSR1-CREM gene fusion. EWSR1 break-apart FISH demonstrate a cell with split red and green signals, indicative of a translocation. This case demonstrated split positivity for EWSR1, and fusion with CREM was confirmed.

\section{Discussion}

CCC is a low-grade malignancy with a good prognosis after complete surgical excision. Local recurrence and nodal metastases may occur, but distant metastasis and death due to disease are rare [2]. Clinical features, staining patterns, fusion type, pathological findings, and diagnostic methods reported cases of CCC in the cheek or buccal mucosa are summarized in Tables 1 and 2. The EWSR1-CREM fusion gene has not been previously reported in CCC of the buccal mucosa. Differential diagnosis of CCC based on histopathol- ogy includes mucoepidermoid carcinoma, acinic cell carcinoma, clear cell oncocytoma, epithelial myoepithelial carcinoma, malignant myoepithelioma, and metastatic renal cell carcinoma, all of which show a significant proportion of clear cells $[1,5]$. The clear cell variant of mucoepidermoid carcinoma is positively stained with mucicarmine for tumor cells, which can be very helpful for highlighting the mucous cells and distinguishing them from other clear cell neoplasms [6]. Acinic cell carcinoma contains zymogen granules, which are PAS-positive and diastase resistant [7]. DOG1 and SOX10 are immunopositive in acinar and 


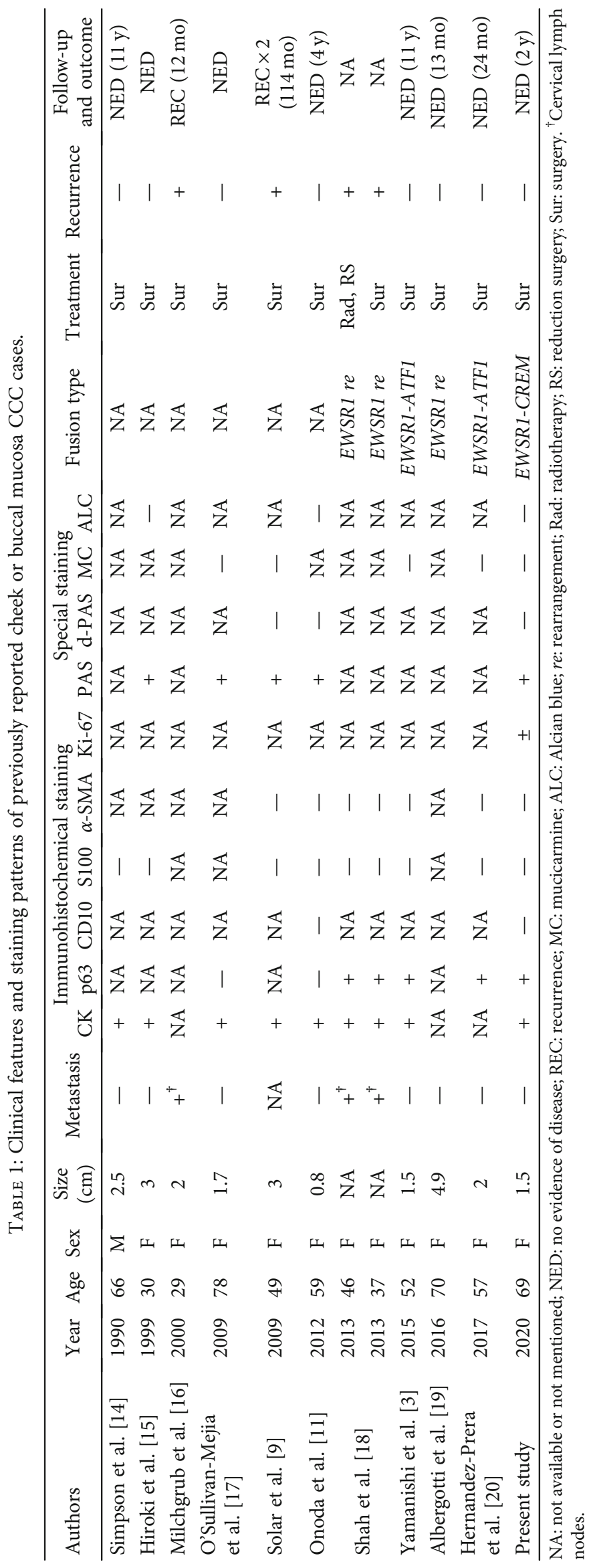


TABLE 2: Pathological findings and diagnostic methods of previously reported cheek or buccal mucosa CCC cases.

\begin{tabular}{|c|c|c|c|c|c|c|c|}
\hline \multirow{2}{*}{ Authors } & \multicolumn{6}{|c|}{ Findings } & \multirow{2}{*}{ Diagnosis } \\
\hline & Solid sheets & Nests & Cords & Trabeculae & Hyalinizing stroma & Ducts and gland-like spaces & \\
\hline Simpson et al. [14] & + & + & + & NA & + & $\mathrm{NA}$ & IHC, EMS \\
\hline T Hiroki [15] & + & NA & NA & NA & + & + & IHC, EMS \\
\hline Milchgrub et al. [16] & NA & + & + & + & + & NA & FNA \\
\hline O'Sullivan-Mejia et al. [17] & NA & + & + & + & + & NA & IHC \\
\hline Solar et al. [9] & + & + & + & + & + & NA & IHC \\
\hline Onoda et al. [11] & + & NA & + & NA & + & NA & IHC \\
\hline \multirow{2}{*}{ Shah et al. [18] } & + & + & NA & + & + & NA & IHC, FISH \\
\hline & + & + & NA & + & + & NA & IHC, FISH \\
\hline Yamanishi et al. [3] & + & + & + & + & + & NA & IHC, RT-PCR \\
\hline Albergotti et al. [19] & NA & + & + & NA & + & NA & FISH \\
\hline Hernandez-Prera [20] & + & + & NA & + & + & NA & IHC, FISH \\
\hline Present study & + & + & + & + & + & + & IHC, FISH \\
\hline
\end{tabular}

intercalated duct cells. Acinic cell carcinoma is usually immunonegative for mammaglobin [8]. Clear cell oncocytoma has a PAS-positive and diastase-PAS-negative cytoplasm. Unlike CCC, it is encapsulated or circumscribed, and the clear cells have a marginal rim of cytoplasm that retains eosinophilic granules. The tumor cells are also positively stained with phosphotungstic acid-hematoxylin and show strong immunohistochemical staining for mitochondria [9]. Epithelial myoepithelial carcinoma and malignant myoepithelioma express $S 100$ protein, $\alpha$-smooth muscle actin ( $\alpha$-SMA), and SOX10 $[6,10]$. SOX10 is positive for myoepithelial carcinoma [10]. Renal cell carcinoma shows immunopositivity for cytokeratins, vimentin, and CD10 [6]. CCC is characterized by trabeculae, cords, or irregular solid nests surrounded by a hyalinized stroma. The tumor cells have clear cytoplasm and circular or polygonal nuclei [11]. Perineural and bone invasion are common, and ducts and gland-like spaces may be evident. CCC is positive for CKs and p63 and negative for other myoepithelial markers. Intracytoplasmic fine granules that give a diastase-sensitive positive PAS reaction are present [2]. The use of special stains and immunohistochemistry, along with careful histological examination of the tumor, in order to identify the typical features found in each of these neoplasms, is helpful for establishing a correct diagnosis [5]. Specific gene fusions have been found to play a definitive role in tumorigenesis. The 2017 WHO classification states that the EWSR1-ATF1 fusion gene can be identified in CCC [2] and is the most reliable tool for differentiating CCC from other histologically similar tumors. In the present case, however, it could not be detected by RT-PCR. Furthermore, the CRTC1/3-MAML2 fusion gene characteristic of mucoepidermoid carcinoma was not detected. FISH, performed to search for genetic abnormalities, demonstrated split positivity for EWSR1, and fusion with the cAMP response element modulator (CREM) was confirmed. Recurrent gene fusions involving EWSR1 with members of the cAMP response element binding protein (CREB) family (ATF1 and CREB1) have been reported in a diverse group of tumors including angiomatoid fibrous histiocytoma, soft tissue and gastrointestinal clear cell sarcoma, primary pulmonary myxoid sarcoma, and hyalinizing clear cell carcinoma of the salivary gland [12]. $C R E B$ can bind to a few thousand gene promoters that contain CRE (cAMP response element), although it remains unknown what fraction of these genes is also functionally regulated upon this binding. CREM belongs to the CREB family (ATF1, CREB1, and CREM) of transcription factors [12]. The structure and biological functions of both CREM and $A T F-1$ are similar to $C R E B$, which forms heterodimers with $A T F-1$ or CREM [13]. In the present case, EWSR1 was fused with one of the CREB family members, CREM. To our knowledge, there are 3 reported cases of hyalinizing clear cell carcinomas of EWSR1-CREM fusion [4], but it has not been reported previously in buccal mucosa. The present case of CCC shows that CREM may replace ATF1 as an EWSR 1 fusion partner. For future characterization of tumors, molecular diagnostic assays will become increasingly important in addition to the use of special staining and immunohistochemistry.

\section{Conclusion}

CCC is a rare minor salivary gland tumor exhibiting lowgrade malignancy. The diagnosis of clear cells in salivary glands can be challenging and the differential diagnosis being quite broad. However, testing for any EWSR1 translocation combined with specific histological staining may be a new reliable method for distinguishing CCC from other salivary gland tumors. Here, we have reported an extremely rare case of clear cell-rich salivary gland carcinoma of the buccal mucosa.

\section{Conflicts of Interest}

All authors have no conflicts of interest to declare.

\section{Acknowledgments}

The authors would like to thank Ms. Satoko Baba at the cancer institute for her technical support. 


\section{References}

[1] S. Milchgrub, D. R. Gnepp, F. Vuitch, R. Delgado, and J. Albores-Saavedra, "Hyalinizing clear cell carcinoma of salivary gland," American Journal of Surgical Pathology, vol. 18, no. 1, pp. 74-82, 1994.

[2] B. M. Wenig, D. Bell, S. Chiosea, H. Inagaki, and R. Seethala, "Clear cell carcinoma," in World Health Organization Classification of Head and Neck Tumours, A. K. El-Naggar, J. K. C. Chan, J. R. Grandis, T. Takata, and P. J. Slootweg, Eds., IARC Press, Lyon, 2017.

[3] T. Yamanishi, K. Kutsuma, and K. Masuyama, "A case of hyalinizing clear cell carcinoma, so-called clear cell carcinoma, not otherwise specified, of the minor salivary glands of the buccal mucosa," Case Reports in Otolaryngology, vol. 2015, Article ID 471693, 7 pages, 2015.

[4] E. Chapman, A. Skalova, N. Ptakova et al., "Molecular profiling of hyalinizing clear cell carcinomas revealed a subset of tumors harboring a novel EWSR1-CREM fusion," American Journal of Surgical Pathology, vol. 42, no. 9, pp. 1182-1189, 2018.

[5] T. K. Chao, C. C. Tsai, S. Y. Yeh, and J. E. Teh, "Hyalinizing clear cell carcinoma of the hard palate," The Journal of Laryngology \& Otology, vol. 118, no. 5, pp. 382-384, 2004.

[6] E. Maiorano, M. Altini, and G. Favia, "Clear cell tumors of the salivary glands, jaws, and oral mucosa," Seminars Diagnostic Pathology, vol. 14, no. 3, pp. 201-212, 1997.

[7] K. Pujary, S. Rangarajan, D. R. Nayak, R. Balakrishnan, and V. Ramakrishnan, "Hyalinizing clear cell carcinoma of the base of tongue," International Journal of Oral and Maxillofacial Surgery, vol. 37, no. 1, pp. 93-96, 2008.

[8] R. H. W. Simpson, S. Chiosea, N. Katabi, I. Leivo, P. Vielh, and M. D. Williams, "Acinic cell carcinoma," in World Health Organization Classification of Head and Neck Tumours, A. K. EI-Naggar, J. K. C. Chan, J. R. Grandis, T. Takata, and P. J. Slootweg, Eds., IARC Press, Lyon, France, 2017.

[9] A. A. Solar, B. L. Schmidt, and R. C. K. Jordan, "Hyalinizing clear cell carcinoma," Cancer, vol. 115, no. 1, pp. 75-83, 2009.

[10] M. S. Hsieh, Y. H. Lee, and Y. L. Chang, "SOX10-positive salivary gland tumors: a growing list, including mammary analogue secretory carcinoma of the salivary gland, sialoblastoma, low-grade salivary duct carcinoma, basal cell adenoma/adenocarcinoma, and a subgroup of mucoepidermoid carcinoma," Human Pathology, vol. 56, pp. 134-142, 2016.

[11] M. Onoda, K. Seki, T. Ikari, W. Kumamaru, T. Sugiura, and K. Shirasuna, "A case of clear cell carcinoma, not otherwise specified (NOS) of the buccal mucosa," Japanese Journal of Oral and Maxillofacial Surgery, vol. 58, no. 5, pp. 288-291, 2012.

[12] Y. C. Kao, Y. S. Sung, L. Zhang et al., "EWSR1 fusions with $C R E B$ family transcription factors define a novel myxoid mesenchymal tumor with predilection for intracranial location," American Journal of Surgical Pathology, vol. 41, no. 4, pp. 482-490, 2017.

[13] X. Wu, C. Spiro, W. G. Owen, and C. T. McMurray, "cAMP Response Element-binding Protein Monomers Cooperatively Assemble to Form Dimers on DNA," Journal of Biological Chemistry, vol. 273, no. 33, pp. 20820-20827, 1998.

[14] R. H. W. Simpson, P. T. L. Sarsfield, T. Clarke, and A. V. Babajews, "Clear cell carcinoma of minor salivary glands," Histopathology, vol. 17, no. 5, pp. 433-438, 1990.
[15] H. Toyoda, K. Yamaguchi, K. Masumoto, T. Koyama, H. Fukuda, and K. Hashimoto, "A case of hyalinizing clear cell carcinoma of the cheek with thirteen-year delay of the disease," Journal of the Japanese Stomatological Society, vol. 48, no. 6, pp. 498-502, 1999.

[16] S. Milchgrub, F. Vuitch, M. Hossein Saboorian, A. Hameed, $\mathrm{H}$. Wu, and J. Albores-Saavedra, "Hyalinizing clear-cell carcinoma of salivary glands in fine-needle aspiration," Diagnostic Cytopathology, vol. 23, no. 5, pp. 333-337, 2000.

[17] E. D. O'Sullivan-Mejia, H. D. Massey, W. C. Faquin, and C. N. Powers, "Hyalinizing clear cell carcinoma: report of eight cases and a review of literature," Head and Neck Pathology, vol. 3, no. 3, pp. 179-185, 2009.

[18] A. A. Shah, R. D. LeGallo, A. van Zante et al., "EWSR1 genetic rearrangements in salivary gland tumors," American Journal of Surgical Pathology, vol. 37, no. 4, pp. 571-578, 2013.

[19] W. G. Albergotti, E. A. Bilodeau, J. K. Byrd, M. M. Mims, S. Lee, and S. Kim, "Hyalinizing clear cell carcinoma of the head and neck: case series and update," Head \& Neck, vol. 38, no. 3, pp. 426-433, 2016.

[20] J. C. Hernandez-Prera, R. Kwan, J. Tripodi et al., "Reappraising hyalinizing clear cell carcinoma: a population-based study with molecular confirmation," Head \& Neck, vol. 39, no. 3, pp. 503-511, 2017. 